\title{
Retraction note: Comparison on grain refinement efficiency of peritectic and eutectic alloying elements on pure Aluminium
}

\section{R. Haghayeghi and P. Kapranos}

\author{
Retraction note: Met. Mater. Int., Vol. 20, No. 4, pp. 713-717 (2014) \\ DOI: $10.1007 / \mathbf{s} 12540-014-4016-z$
}

This article has been retracted at the request of the editorial board of Metals and Materials International. The article was examined following the COPE guidelines with regard to suspected plagiarism in a published manuscript.

The article contains a substantial amount of taken from a previously published article with no acknowledgement of the source.

Fig. 2 (a) and (b) and Fig. 3 are taken from:

Revisiting the role of peritectics in grain refinement of Al alloys

Feng Wang, Zhilin Liu, Dong Qiu, John A. Taylor, Mark A. Easton, Ming-Xing Zhang

Acta Materialia 61 (2013) 360-370

Fig. 2 (a) and (b) are taken from Fig. 9 (a) and (c). In the original source, the figure is related to cooling curves of pure Al and Al$0.40 \mathrm{wt} \% \mathrm{~V}$, but in the paper in question it is presented as cooling curves of Al-1.6 wt\% Cu and Al-0.18 wt\% V

Fig. 3 is taken with slight modification from Fig. 8 (c) and (d). In the original source, the figure is related to SEM results for Al-0.40 $w t \% \mathrm{~V}$, but in the paper in question it is presented as SEM results for Al-0.18wt\% V

The online version of the original article can be found under doi: 10.1007/s12540-014-4016-z

R. Haghayeghi* and P. Kapranos Department of Materials Engineering, Tehran Science and Research Branch, Islamic Azad University, Tehran, Iran e-mail: rhaghayeghi@gmail.com CKIM and Springer 